\title{
COMMITMENT TO PUBLIC INTEREST AND PUBLIC SERVICE MOTIVATION DEVELOPMENT CHALLENGES: A QUALITATIVE INQUIRY
}

\author{
George B. Amegavi \\ Ph.D. Candidate, Department of Geography, Environment \\ \& Population The University of Adelaide. \\ Address: SA 5005 Australia. \\ E-mail: george.amegavi@adelaide.edu.au
}

\section{James K. Mensah}

Ph.D., Lecturer, Department of Public Administration and Health Services Management, University of Ghana Business School. Address: P.O. Box LG 78, Legon, Accra, Ghana. E-mail: jamesmensah@ug.edu.gh

\begin{abstract}
The use of qualitative research in Public Service Motivation research is growing and its impact on the field is beginning to be felt. This study contributes to our understanding of PSM by exploring the dimension of "commitment to public interest" and the challenges to development in Ghana. The analysis of 34 semi-structured in-depth interviews conducted with employees of the Financial Intelligence Centre demonstrates that commitment to public interest is influenced by leadership actions and organizational culture. The outcome of this paper is useful for public organizations in their attempt to improve employee commitment and productivity in the public sector.
\end{abstract}

Keywords: public servants; public service motivation; Ghana; public sector; qualitative research; public interest.

Citation: Amegavi, G. B. \& Mensah, J. K. (2020). Commitment to Public Interest and Public Service Motivation Development Challenges: A Qualitative Inquiry. Public Administration Issues, no 6 (Special Issue II, electronic edition), pp. 67-83 (in English), DOI: 10.17323/1999-5431-2020-0-6-67-83.

\section{Introduction}

Researchers and practitioners have been interested in the possibility that some individuals may have a unique conviction that predisposes them to serve and safeguard the public interest. Public service motivation (PSM) symbolizes 
an example of theory development in public administration on the predisposition that individuals could have towards public service. The term "public service motivation" originated in the 1970s in discussions of public service ethics (Buchanan, 1975; Rainey, 1982) that investigated the differences in reward motivations between public and private sector workers. The study concludes that public employees have a greater interest in altruistic or ideological goals. As a theory, PSM has important practical relevance, as it tries to explain the relationship between motivation and public interest (Moynihan \& Pandey, 2007).

According to PSM, public employees are motivated by altruistic intentions to serve the public interest (Asseburg \& Homberg, 2020; Neumann, 2019; Bright, 2008). Public choice theory, however, posits that public servants are selfinterested individuals, trying to maximize their utility and benefits, and aiming to increase their prestige, power, and income, instead of being motivated to serve the state and the public (Hughes, 1994). In contributing to the discourse, Tullock (1976) also argues that public servants are not entirely selfish; they are "partly selfish and partly public-interested" (p. 27). The public interest construct is fundamental to traditional public administration scholarship (Appleby, 1945). This theoretical development in the last few years has been gradually joined by empirical studies as researchers try to operationalize what public interest means for employees, why they develop a strong sense of public service, and how that sense influences their actions (Neumann, 2019; Kim \& Vandenabeele, 2010; Kim, 2006).

Despite the increasing attention to PSM scholarship (Kalgin, 2020; Van der Wal, 2015; Perry \& Hondeghem, 2008), qualitative methodological approaches have received limited attention (Bawole et al., 2018; Ritz et al., 2016). This methodological approach is recommended by Wright (2008) and also provides credible research findings, context realism, and context-relevant examples (Wright \& Grant, 2010; Krefting, 1991). Moreover, qualitative findings tend to be constructive in generating theories about PSM (Yung, 2014). Therefore, qualitative research methods have a significant role to play in PSM scholarship. In light of the above, this paper will attempt to use a qualitative methodological approach to make a modest contribution to the PSM literature. The paper investigates commitment to the public interest as a PSM dimension and PSM development challenges in Ghana.

The rest of the paper is organized as follows: section two discusses the concept of PSM, public service in Ghana, and PSM in Africa; section three provides the research setting and methodology; the study findings and discussions are provided in section four; and the last section provides the conclusion and policy implications.

\section{Literature review}

\section{Public Service Motivation}

Public service motivation is one of the oldest and most discussed topics in public administration (Perry \& Hondeghem, 2008; Alonso \& Lewis, 2001). This could be attributed to the relevance of PSM to productivity, account- 
ability, improved management practices, and trust in government but not just to motivation (Neumann, 2019; Moynihan \& Pandey, 2007). The discipline has suggested that public employees should be and are motivated by the desire to help the public (Moynihan \& Pandey, 2007); better defined as the public service ethic (Brewer \& Selden, 1998) or public service motivation (Perry \& Wise, 1990).

PSM is "an individual's predisposition to respond to motives grounded primarily or uniquely in public institutions" (Perry \& Wise, 1990, p. 368). In developing the theory, Perry and Wise (1990) identified three motives for PSM: affective, rational, and normative. Affective motive is derived from a civil servant's ability to identify with the less privileged and those who need State assistance. The rational motive is an understanding of the instrumental process of public service. Meanwhile, the normative motive is premised on accomplishing goals in compliance with values and norms (Andersen et al., 2013). Based on these motives, Perry (1996) developed a scale that consists of four dimensions: attraction to policy-making, commitment to public interest, self-sacrifice, and compassion. Previous studies were using proxy variables to measure PSM and sector comparisons to test for its existence but his approach was a significant improvement (Bright, 2005). Commitment to public interest measures normative motives, attraction to public policy measures rational motives, and both compassion and self-sacrifice measure affective motives (Perry, 2000). The public interest dimension of PSM is based on the duty to serve society and loyalty norms (Perry, 1996). This suggests that public employees are expected to do what is considered best for society. This encompasses a commitment to public values like fairness, honesty, accountability, and social equity. As a result, the public interest dimension has been renamed "commitment to public values" by Kim and Vandenabeele (2010).

However, empirical support of PSM as a motivational force in promoting pro-organizational behavior and public interest has been mixed (Asseburg \& Homberg, 2020; Kalgin, 2020; Bright, 2005). Even though some empirical studies have found a positive relationship between PSM and employee behavior (e.g. Piatak \& Holt, 2020; Miao et al., 2019; Kim, 2006; Brewer \& Selden, 1998), the relationships in other studies were complicated or non-significant (Bright 2008; Alonso \& Lewis, 2001). For example, Scharz, Eva, and Newman (2020) found that leadership is significantly positively related to employee PSM and job performance of civil servants in China. Leisink and Steijn (2009) also established that higher levels of PSM were associated with a greater desire to exert effort at work. In a cross-country study, Meyer-Sahling et al., (2020) reported that merit competitions are associated with greater PSM levels but permanent contracts have no significant effect in two countries and a lower effect in one country. Furthermore, another study by Choi (2004) to investigate the relationship between ethical behavior and PSM in the United States, found that commitment to public interest did not influence the ethical reasoning level of public servants.

Despite the expectation on public employees to promote public interest as espoused by the PSM concept, there exist some obstacles which hinder these expec- 
tations and PSM development in many public organizations. For instance, a study by Paarlberg and Lavigna (2010) found that bad leadership practices do not encourage prosocial motivation, hence, hinders employee PSM development. Another challenge to PSM development is the culture and environment in which employees work. In a study to explore the role of organizations in fostering public service motivation, Moynihan and Pandey (2007) found that excessive red tape discourages public employees and makes them feel they are not serving the public interest, which affects the PSM levels. This evidence is corroborated by Cooke et al., (2019). Other challenges to PSM development include lack of training, poor remuneration, (Yung, 2014), lack of trust in leadership (Lee et al., 2020), and corruption (Jacobson, 2011). From the above, although public employees are expected to promote the public interest, there remain some issues that need to be addressed to achieve this.

\section{Public service in Ghana and PSM in Africa}

The British colonial government fashioned its Ghanaian public administration after the British Parliamentary Civil Service System and this was passed to an independent Ghana in 1957. When the British relinquished their political and administrative control in 1957, Ghana became the first sub-Saharan country in colonial Africa to gain independence. Despite moving to a Presidential system, Ghana's public service structure still to a large extent replicates its British colonial origins. Ghana's public service is considered one of the oldest and most professional fields of public administration in sub-Saharan Africa (Huq, 1989). The period immediately before independence in 1957 to the mid-1970s was described as the "good days' of the public service because public servants were adequately remunerated and resourced, plus their security of tenure as well as their anonymity were guaranteed (Ayee, 2001). These factors summed up to produce an enabling work environment that stimulated the highest degree of performance and productivity. These factors attracted people to work in the public sector.

Since independence, Ghana's public service has undergone significant changes. Public servants once described as efficient, enjoyed high prestige after independence have now been described as offering poor services and being corrupt (Owusu, 2006). Commitment to public sector goals is manifested in constructs such as PSM (Perry \& Wise, 1990) and public service ethos (Rainey, 1982) which are the subject of most research in recent times. Therefore, are Ghanaian public servants self-interested? Do they try to maximize their benefits and increase their power and wealth, instead of serving the public interest? These are questions and concerns that require answers. Most times, public servants do not simply have one motivation, be it PSM or any other motivation, but rather a combination of motivations (Taylor \& Taylor, 2011). It would be of utmost interest to the government of Ghana and the citizenry to know whether Ghanaian public servants have the required level of PSM-value or ethics.

Preliminary studies on PSM started in the United States (Van Der Wal, 2015). Most of the studies have been done in developed countries (Bawole et al., 2018; Ritz et al., 2016), especially in the United States and Europe (e.g. Asseburg 
\& Homberg, 2020; Belle, 2013; Leisink \& Steijn, 2009). In recent years, PSM studies have been gradually increasing in the Asian context (e.g. Lee, 2020; Aqli \& Syafi'I, 2019; Chen et al., 2014). However, there is a paucity of PSM studies in Africa (Bawole et al., 2018). For instance, in their systematic review of PSM research, Ritz et al. (2016) reported that 27.5\% of PSM studies are from the United States, $43.4 \%$ from Europe, $17.2 \%$ from Asia, and the remaining 11.9\% from the rest of the other regions of the world including Africa. They further revealed that there were only three studies from Africa that used samples from 11 different African countries. This demonstrates that there is little research on PSM in Africa. The paucity of PSM studies provides an incentive for empirical PSM studies in the region. Therefore, this paper attempts to make a modest contribution to the PSM literature by bringing in an integrated dimension from Ghana, a sub-Saharan African country.

\section{The study context}

This research was conducted in the Financial Intelligence Centre (FIC). The FIC is a public institution in Ghana established under Section 4 of the AntiMoney Laundering Act, 2008 (Act, 749), with the mandate to assist in the combat of money laundering, terrorism financing, and the proliferation of weapons of mass destruction. The present research started with the assumption that prosocial behaviours would be present and would differ among the workers of the FIC. Besides having the mandate as an anti-corruption and anti-money laundering institution, employees of the institution have different educational backgrounds and technical competencies.

\section{Methodology}

An interpretive perspective was adopted for the study. Hence, a qualitative methodological approach was used to find answers to the research question on motivating factors for entry and the challenges to the development of PSM among public employees in Ghana. This approach is a different method from the survey designs used in previous studies of antecedents and relationships of PSM (e.g. Meyer-Sahling et al., 2020; Lee, 2020; Bullock et al., 2015; Leisink \& Steijn, 2009). Adopting a qualitative approach facilitates the use of information from diverse sources in answering the why, what, and how questions (Yin, 2003). Similarly, it can help address some of the challenges (Wright, 2008) associated with the lack of consensus on a valid operationalization of PSM (Perry et al., 2010). In exploring complex theoretical concepts like PSM and when the aim is to elucidate patterns of motives about a concept in relation to other complex variables, interviews are considered very appropriate (Kjeldsen, 2012). Although this qualitative research may not bring about statistical generalization, it can certainly aid in understanding the general situation among public officials in Ghana from a qualitative perspective, complementing quantitative research.

A case study design was adopted for the research. Yin (2003) claims that a case study is generally limited to a specific activity and is time-bound, which 
allows the collection of comprehensive data on an issue within a stipulated time. Both secondary and primary sources were the main data sources for the study. The primary data was collected through in-depth semi-structured interviews with 34 employees of the Financial Intelligence Agency (FIC). The study sample came from officers, deputy-managers, and managers. The employees interviewed came from different units and departments. In this research, data saturation was reached after new themes stopped emerging from the interviews.

Because theory building was not the focus of this study but rather interpretation and description, the delineation of the correlations between different theoretical concepts was not used as a criterion of data saturation (Corbin \& Strauss, 2008). The breakdown is presented in the Table. The interviews sought information about the reasons for joining the public service, motivation for staying with the public sector, their commitment to the public interest, and specific factors to PSM development in Ghana's public sector.

The interviews generally lasted between 30 to 45 minutes. The study also conducted a documentary analysis to augment the interview data. The interviews were analysed based on the approach by Miles and Huberman (1994). The analysis started with a thorough reading of each transcript. They were then reviewed for common themes and ideas. The themes were grouped under broad headings focusing on identifying the major ideas brought out by each sentence. The main ideas were labelled or coded, which formed the main analysis categories. Based on this, related sub-categories that were dominant in the responses of interviewees were also set apart for re-evaluation alongside the main categories. The final stage of data analysis was generating categories, themes, and units for analysis that formed the basis of the final study report. To also improve the interpretive validity of the findings, verbatim quotes were used to exemplify the results (Johnson, 1997).

\section{Research Findings}

This paper investigates commitment to public interest as a PSM dimension and PSM developing challenges amongst public employees. The analysis of the data focuses on PSM and reasons for joining the public sector, commitment to the public interest as a PSM dimension, challenges to PSM development in Ghana, and ways to promote PSM development.

\section{Demographic characteristics of respondents}

The demographic characteristics of respondents show that the majority of the respondents were men (55.9\%) and most of them were within the ages of 31-40 (58.8\%). Most of the respondents (61.8\%) had bachelor's degrees. Additionally, most of the participants (68\%) have worked in the agency for more than three years. The years spent in employment could improve an employee's level of experience. This suggests that most of the respondents were experienced and probably understand the public sector environment as well as the issues discussed. 


\section{Demographic characteristics of respondents}

\begin{tabular}{|c|c|c|}
\hline \multicolumn{1}{|c|}{ Gender } & Frequency & $\%$ \\
\hline Male & 19 & 55.9 \\
\hline Female & 15 & 44.1 \\
\hline Age & & 23.5 \\
\hline $20-30$ & 8 & 58.8 \\
\hline $31-40$ & 20 & 11.8 \\
\hline $41-50$ & 4 & 5.9 \\
\hline $51-60$ & 2 & 61.8 \\
\hline Education & 21 & 38.2 \\
\hline Bachelor degree & 13 & \\
\hline Master's degree & & 64.7 \\
\hline Positions & 22 & 23.5 \\
\hline Officers & 8 & 11.8 \\
\hline Deputy-managers & 4 & \\
\hline Managers & & \\
\hline
\end{tabular}

Source: Fieldwork, 2018

\section{PSM and reasons for joining the public sector}

The Ghanaian public perceives public sector employment as flexible and providing high job security with good fringe benefits. Until the introduction of the Single Spine Pay Policy (SSPP) in 2010, the public perceived public employment as a low paid job in Ghana. The introduction of the SSPP led to a review of all public sector salaries leading to a 20\% increase in salaries (Fair Wages and Salaries Commission, 2011). This improvement in salaries led to increased interest from people to work in the public service which was previously associated with poor remuneration. This could imply that most people who joined the public sector after the introduction of the SSPP, probably joined because of the high remuneration but not necessarily to promote the public interest. Illustrating this point, a respondent asserted that:

"Getting a well-paid job in Ghana is not easy. So for me, PSM was not my reason for choosing the public service. I chose the public sector because of the improvement in salaries. I never considered the option to serve the public interest before joining the agency" (male, officer, finance and administration).

Job security is a characteristic associated with public sector employment in Ghana. Job security was a major determinant for the majority of the respondents. However, a significant finding was that most of these respondents were offic- 
ers and deputy-managers. All four managers did not consider job security as a major issue in their job search. This could be attributed to their level of experience and the higher probability of getting a new job. Additionally, although previous studies have reported that PSM is an essential determinant of career choice in the public sector, the study findings show that PSM was not an essential determinant for most of the respondents but rather job security. The quote below reflects the issues as espoused by a respondent:

"As a working mother, I needed a job that provides me flexible working hours and job security and the public sector is my best bet. The private sector was never an option for me because it won't provide that" (female, officer, analysis department).

Limited employment opportunities in Ghana was another reason why people choose to join the public service, the study revealed. Although most job seekers would prefer the option to decide where to work, the limited employment opportunities for university graduates is making this almost impossible. This is how a respondent describes it:

"After my national service, I was unemployed for three years and finding a job was a major hurdle for me. So when the opportunity came to work in the public service I took it because I needed a job to make a living" (female, officer, finance and administration).

These findings suggest that the motivation to serve the public does not appear to be an important determinant for public servants when making a career choice to work in the public sector in Ghana. What matters to them is the opportunity to have a stable job and improve their living conditions.

\section{Commitment to public interest as a PSM dimension}

Public employees are expected to act in the interests of society and promote the public interest. This places enormous pressure on them in the execution of their job roles. Commitment to the public interest is an obvious way to promote the public interest. While numerous factors can drive the desire of people to work in public service, it was revealed that commitment to public interest seems to be a prevalent motivation among the respondents. This probably lies in their empathy for people which appears to be a general Ghanaian characteristic.

Public service as a civic duty. This category explores the principle that citizens owe some allegiance to society and act as a motivating factor that influences public employees' motivation. Regarding civic duty, some respondents find the idea of allegiance to society and the resulting expectations motivating. One employee asserted:

"As public officials, we owe our allegiance to society because we are paid through the taxes citizens pay. Therefore, this places an obligation on us to promote the interest of our society" (female, deputy-manager, finance and administration). 
It is significant to the respondents that they are able to contribute their skills and technical knowledge to making public service meaningful. Moreover, they want to create a positive impression on the citizens they serve and be recognized as public officials who deliver efficient public service. In this context, the link between technical expertise, expert knowledge of public service, and public empathy is frequently mentioned. Some of the respondents have found ways to serve the public and bring their expert skills and knowledge in the face of scarce resources. A respondent underscored this point:

"As the head of this unit, we have limited officials so I have developed a flexible break schedule to ensure that we always have officials attending to people who come to our office" (male, deputy-manager, compliance department).

Altruistic norm is an integral part of PSM. The respondents were asked if they would still go ahead and do what is best for their society, even if it would harm their interests. The findings were interesting, revealing a limited motivation among most respondents to do so. For a few, it is motivating because somebody probably must rise to the occasion and be making those sacrifices. Some respondents were of the view that it was not worth it. Commenting on the issue, a respondent argued:

"Nobody cares about what goes on in this country and look at how the politicians and senior public officials carry themselves around. Nobody is willing to sacrifice anything. Why should I?" (Male, officer, analysis department).

Another respondent also added that:

"Taking actions like that will only lead to victimization from colleagues and senior officials because you will end up fighting the ills in the system. When this happens you may be transferred or your promotion will be stifled" (male, officer, compliance department).

In sum, the issues described suggest that commitment to the public interest is seemingly mixed. Commitment outcomes are contingent on the work environment and culture as well as what is demanded of the public servant. But generally, public employees see the need to promote public interest as a legitimate responsibility for them.

\section{Challenges to PSM development in Ghana}

PSM levels of public officials could be developed when they join the sector. The findings show that most employees who joined the public sector were not generally driven by the motivation to serve the public interest. This suggests that PSM appears not to be a significant factor for joining the public sector in Ghana. The PSM levels of these employees can nonetheless be nurtured. The Government of Ghana has implemented various policies and pro- 
grammes intending to motivate public employees to protect and promote the public interest. For instance, in 2010, the Single Spine Pay Policy was introduced to improve public service remuneration. This has led to a yearly pay rise between 10-20\% (Fair Wages and Salaries Commission, 2018). The objective of the salary increases and the SSPP aims to improve the salaries of public servants to help improve productivity and ameliorate the rising corruption in the sector. Besides, there is an annual performance appraisal to assist employees to improve their performance and also motivate them.

These initiatives appear not to be achieving their intended goals of motivating public employees and creating a sense of responsibility to protect the public interest. The majority of the respondents believe that results of performance appraisals conducted annually are rarely used and not even considered when promoting or increasing the salaries of public sector workers. For example, a respondent lamented:

"It doesn't matter how you perform because people are rarely scored low marks on the performance appraisal scoresheet. So why would I care about putting in more effort and caring about what I do for the sector and the public when I know that won't count in my appraisal. What is important for me is just to remain in the service" (male, officer, monitoring and supervision unit).

Performance appraisals performed annually in Ghana's public service are very lenient and on most occasions "rubber stamp" processes to satisfy administrative and policy requirements. Consequently, these processes are bedeviled with irregularities and fraud due to their subjective and reward-driven nature.

Ghana is a democratic nation that observes the rule of law. Therefore, citizens expect the government and public servants to consult them in the formulation and implementation of public policies to ensure that their interest is promoted. This has not been the case over the years in Ghana. Past governments have formulated and implemented with the help of public servants bad policies that have caused financial loss to the State. What do public officials consider as "public interest"? Helping politicians to the detriment of society or ensuring that public interest is promoted. Moreover, citizens perceive public servants as corrupt. This negative perception about public servants was confirmed by opinion polls with $91.4 \%$ of respondents ranking corruption in the public sector of Ghana as high (NCCE, 2017). Since PSM is not the motivating factor for most workers joining the public service, coupled with the negative public perception of corruption in the public sector, it might be challenging to nurture PSM in public officials after joining the public sector.

The leadership in Ghana has verbally supported the urgency to promote the public interest. However, the commitment and will to do so appears to be absent. This suggests that the development of PSM in Ghana's public service has only received lip-service support from both political and institutional leaders. According to participants, the actions and inactions of their superiors are significant since their actions influence their PSM development. They tend to look at their leaders for motivation and direction. However, it was revealed that some po- 
litical government appointees and supervisors in the organization are engaged in corrupt practices. This implies that such leaders engage in practices that promote their personal interest to the detriment of the public interest. Significantly, when these appointees are exposed, they are only reassigned or transferred and seldom face any prosecution. These acts impede PSM development and further erode gains made, if any.

Public institutions are associated with rigid bureaucratic and hierarchical structures with limited room for functional freedom and proactivity. These bureaucratic and hierarchical structures have the potential to impede PSM development (Gailmard, 2010). This was reiterated by a respondent who lamented that the bureaucratic structures tend to limit employee initiatives as they are required to obey and take orders from their superiors. Therefore, people who join the public sector with innovative ideas and a high level of motivation to promote the public interest could get frustrated by the public sector machinery due to its inflexible nature. Consequently, most of these employees might gradually become disinterested in public service as their motivation is consistently frustrated by the rigid bureaucratic and hierarchical structures. These challenges have the potential to dampen the innovative drive of public servants, which is likely to weaken their PSM levels.

\section{Discussion}

Recent studies have underscored the significant roles that PSM can play in determining employee performance in public sector organizations (Miao et al., 2019; Bullock et al., 2015; Kim, 2006; Alonso \& Lewis, 2001; Perry, 1996) and the challenges to PSM development (Barsoum, 2016; Yung, 2014; Paarlberg \& Lavigna, 2010; Paarlberg, Perry \& Hondeghem, 2008). These studies highlight the facilitating role PSM plays. Recruiting employees with high PSM levels into the public sector has been a continual challenge for many public sector managers especially in developing countries. The study supports the hypothesis that PSM can be used to examine why people choose to work in the public sector (Moynihan \& Pandey, 2007; Brewer \& Selden, 1998). Contrary to the public interest dimension of PSM based on the duty to serve society and loyalty norms (Perry, 1996), the findings of this study do not support this view, rather, it shows that job security and remuneration packages are the dominant factors considered when making a career choice to work in the public sector. Public sector employment provides stable job opportunities and the introduction of the SSPP has led to increases in public sector salaries in Ghana. It is also important to mention that having self-interested motives for choosing to work in the public sector might not necessarily make it impossible to have simultaneous public-interested motivations (Le Grand, 2003). This result could be attributed to the poor economic conditions, high poverty rates, and difficulties associated with getting a job in Ghana due to the limited job opportunities in the country. Therefore, these conditions might be influencing people to consider job stability and pay conditions when making career choices but not necessarily promoting the public interest. 
This finding confirms previous research results from Egypt (Barsoum, 2016) and Hong Kong (Yung, 2014) but contradicts the study by Bright (2008) from the United States.

Organizational culture and leadership actions were identified as factors impeding PSM development in the case study organization. The findings provide additional support for current efforts in the literature to examine the factors that impede PSM development in public organizations (Schwarz et al., 2020; Yung, 2014; Bellé, 2013; Paarlberg \& Lavigna, 2010). These results make the claim by Paarlberg, Perry, and Hondeghem more significant, that is, leaders can foster or impede PSM development when "they raise their followers' consciousness about idealized goals by articulating high standards of moral and ethical conduct, and acting as prosocial models' $(2008$, p. 282). This suggests that when leaders fail to act as prosocial models, the probability that high PSM employees might start showing low PSM motives becomes quite high. This is probably because the motivation to promote the public interest and act ethically might not appear rewarding and relevant due to the prevailing organizational culture supported by the leadership. This may cause low job satisfaction among some employees and reduce their levels of commitment to the organization which might lead to low productivity in the long run. As a result, this study supports the claim that leadership and organizational culture are important factors in employee PSM development. When employees see that their leaders are showing prosocial behavior, it motivates them to also show similar behaviours and this promotes their level of PSM. These results are consistent with other research that reveals that employee PSM levels can either be improved or reduced by the prevailing organizational culture, employee knowledge about events in their organization, and leadership behaviour (Lee et al., 2020; Ritz \& Brewer, 2013; Kjeldsen, 2012).

\section{Conclusion}

There is a need to provide clearer guidance on how PSM knowledge can be used in practice, given the capacity of PSM as a theory for predicting employee commitment to public interest. The study aimed to investigate commitment to public interest as a PSM dimension and PSM development challenges in Ghana. The study makes some modest contribution to advancing scholarly understanding of PSM in the African context. The research empirically supports the argument that PSM is a unique construct for tapping into the unique areas of motivation that differentially predict the behavior of public officials in theoretically consistent ways. In this research, commitment to public interest is not the central determinant for joining the public service. The key factors that employees considered when joining the public service were job security and remuneration packages. Additionally, organizational culture and leadership were two important factors with the potential to facilitate or impede PSM development in public organizations. PSM emphasizes the duty of public officials to promote the public interest in the dispensation of their duty. Making PSM practically relevant will require more research and information. The study concludes that more 
effective approaches to motivating public employees must take into consideration the complexities and diversities of the public sector workforce and develop strategies that present opportunities that motivate employees who are interested in opportunities that public sector work naturally provides and opportunities for workers who are also interested in intangible rewards. In addition, strong and committed leadership is required for the successful development of public sector ethos that would nurture PSM amongst public sector workers. Therefore, initiatives to develop PSM amongst public workers may not achieve anything worthwhile beyond the normative objective until senior officials display exemplary leadership and prosocial behaviours. It is important to point out that the study had some limitations. First, the study uses data from one public agency in Ghana which may limit the application and generalization across other public institutions in Ghana. This provides avenues for future research to conduct comparative studies using samples from different public organizations or different levels of government such as local and central governments. Second, the research falls under the standard list of common method biases due to it being a behavioral study (Podsakoff et al., 2003) and its relevance could be overestimated in the existing literature (Spector, 2006). However, the objective of the study has been achieved, because the aim was to investigate commitment to the public interest as a PSM dimension and PSM development challenges, rather than to generalize the results across the country.

\section{Recommendations to promote PSM development}

Culture defines what the next generation does. The development of personal values is achieved through social interactions in societies and organizations. Therefore, the development and enhancement of the PSM of the next generation of public servants should be promoted through the introduction of PSM values in the educational curriculum as well as the training organized for public sector workers. This should also be included in civic education for the general public to develop the perception that working in either the public or private sector is synonymous with serving the public (Yung, 2014). This will make people understand and appreciate that promoting the interest of the public is not the sole preserve of public servants but will require support from the private sector

Regarding the challenge of bureaucracy, inter-sectoral and intra-departmental collaborations should be encouraged. The relevance of developing work structures that improve self-regulation through empowerment and participatory decision-making is that they promote PSM amongst public sector workers (Pearlberg et al., 2008). Encouraging frequent interactions between subordinates and superiors creates room for engagements and dialogue about institutional challenges; leading to a better understanding of institutional challenges (read more about this here: Amegavi et al., 2018). This also tends to create room for innovation and improvements in organizational operations.

Lastly, an important tactic in encouraging the development of PSM amongst public sector workers is to highlight PSM in the reward, promotion, and performance appraisal systems. Non-task related issues have been ignored in perfor- 
mance appraisal processes (Gruman \& Saks, 2011), therefore including observations of PSM behavior in performance appraisal systems as a strategy to promote PSM development could encourage and develop employee PSM. However, this would probably depend on how the indicators of PSM are developed to merge with the indicators of the performance appraisal system since it has the potential to affect the whole process and its usefulness in promoting PSM.

\section{REFERENCES}

1. Alonso, P. \& Lewis, G.B. (2001). Public Service Motivation and Job Performance: Evidence from the Federal Sector. The American Review of Public Administration, vol. 31, no 4, pp. 363-380.

2. Amegavi, G.B., Bawole, J.N. \& Buabeng, T. (2018). The Dynamics of E-Government Enactment in a Developing Country Public Sector Organisation: Evidence from Ghana. International Journal of Electronic Governance, vol. 10, no 1, pp. 74-92.

3. Andersen, L.B., Jørgensen, T.B., Kjeldsen, A.M., Pedersen, L.H. \& Vrangbæk, K. (2013). Public Values and Public Service Motivation: Conceptual and Empirical Relationships. The American Review of Public Administration, vol. 43, no 3, pp. 292-311.

4. Appleby, P.H. (1945). Big Democracy. AA Knopf New York.

5. Aqli, Z. \& Syafi'i, A. (2019). Public Employees Risk Aversion and Organizational Citizenship Behavior: The Effects of Ethical Leadership, Work Culture and Public Service Motivation. Public Administration Issues, no 6 (Special Issue II, electronic edition), pp. 7-22.

6. Asseburg, J. \& Homberg, F. (2020). Public Service Motivation or Sector Rewards? Two Studies on the Determinants of Sector Attraction. Review of Public Personnel Administration, vol. 40, no 1 , pp. 82-111.

7. Ayee, J.R. (2001). Civil Service Reform in Ghana: A Case Study of Contemporary Reform Problems in Africa. African Journal of Political Science/Revue Africaine de Science Politique, pp. 1-41.

8. Bawole, J.N., Mensah, J.K. \& Amegavi, G.B. (2018). Public Service Motivation Scholarship in Africa: A Systematic Review and Research Agenda. International Journal of Public Administration, pp. 1-12.

9. Barsoum, G. (2016). The Public Sector as the Employer of Choice Among Youth in Egypt: The Relevance of Public Service Motivation Theory. International Journal of Public Administration, vol. 39, no 3, pp. 205-215. 
10. Bellé, N. (2013). Experimental Evidence on the Relationship Between Public Service Motivation and Job Performance. Public Administration Review, vol. 73, no 1, pp. 143-153.

11. Brewer, G.A. \& Selden, S.C. (1998). Whistleblowers in the Federal Civil Service: New Evidence of the Public Service Ethic. Journal of Public Administration Research and Theory, vol. 8, no 3, pp. 413-440.

12. Bright, L. (2008). Does Public Service Motivation Really Make a Difference on the Job Satisfaction and Turnover Intentions of Public Employees?. The American Review of Public Administration, vol. 38, no 2, pp. 149-166.

13. Bright, L. (2005). Public Employees with High Levels of Public Service Motivation: Who Are They, Where Are They, and What Do They Want?. Review of Public Personnel Administration, vol. 25, no 2, pp. 138-154.

14. Buchanan, B. (1975). Red-Tape and the Service Ethic: Some Unexpected Differences Between Public and Private Managers. Administration \& Society, vol. 6, no 4, pp. 423-444.

15. Bullock, J.B., Stritch, J.M. \& Rainey, H.G. (2015). International Comparison of Public and Private Employees' Work Motives, Attitudes, and Perceived Rewards. Public Administration Review, vol. 75, no 3, pp. 479-489.

16. Chen, C.A., Hsieh, C.W. \& Chen, D.Y. (2014). Fostering Public Service Motivation through Workplace Trust: Evidence from Public Managers in Taiwan. Public Administration, vol. 92, no 4, pp. 954-973.

17. Choi, D. L. (2004). Public Service Motivation and Ethical Conduct. International Review of Public Administration, no 8, pp. 99-106.

18. Cooke, D.K., Brant, K.K. \& Woods, J.M. (2019). The Role of Public Service Motivation in Employee Work Engagement: A Test of the Job Demands-Resources Model. International Journal of Public Administration, vol. 42, no 9, pp. 765-775.

19. Corbin, J. \& Strauss, A. (2015). Basics of Qualitative Research. Thousand Oaks, CA: Sage.

20. Fair Wages and Salaries Commission (FWSC) (2011). Available at: http://fairwages.gov.gh/ (accessed: 15 December 2020).

21. Gailmard, S. (2010). Politics, Principal-Agent Problems, and Public Service Motivation. International Public Management Journal, vol. 13, no 1, pp. 35-45.

22. Gruman, J.A. \& Saks, A.M. (2011). Performance Management and Employee Engagement. Human Resource Management Review, vol. 21, no 2, pp. 123-136.

23. Hughes, O.E. (1994). Public management and administration. London, England: Macmillan Press.

24. Huq, M.M. (1989). The Economy of Ghana. London: Macmillan.

25. Jacobson, W.S. (2011). Creating a Motivated Workforce: How Organizations Can Enhance and Develop Public Service Motivation (PSM). Public Personnel Management, vol. 40, no 3, pp. 215-238.

26. Johnson, R.B. (1997). Examining the Validity Structure of Qualitative Research. Education, vol. 118, no 2, p.282.

27. Kalgin, A. (2020). Antecedents and Outcomes of Public Service Motivation: A Review of the Research Field. Public Administration Issues, no 2, pp. 215-239 (in Russian). 
28. Kim, S. (2006). Public Service Motivation and Organizational Citizenship Behavior in Korea. International Journal of Manpower, vol. 27, no 8, pp. 722-740.

29. Kjeldsen, A.M. (2012). Sector and Occupational Differences in Public Service Motivation: A Qualitative Study. International Journal of Public Administration, vol. 35, no 1, pp. 58-69.

30. Krefting, L. (1991). Rigor in Qualitative Research: The Assessment of Trustworthiness. American Journal of Occupational Therapy, vol. 45, no 3, pp. 214-222.

31. Lee, H.J., Oh, H.G. \& Park, S.M. (2020). Do Trust and Culture Matter for Public Service Motivation Development? Evidence from Public Sector Employees in Korea. Public Personnel Management, vol. 49, no 2, pp. 290-323.

32. Leisink, P. \& Steijn, B. (2009). Public Service Motivation and Job Performance of Public Sector Employees in the Netherlands. International Review of Administrative Sciences, vol. 75, no 1, pp. 35-52.

33. Meyer-Sahling, J., Mikkelsen, K. \& Schuster, C. (2020). Merit Recruitment, Tenure Protections and Public Service Motivation: Evidence from a Conjoint Experiment with 7,300 Public Servants in Latin America, Africa and Eastern Europe. Public Administration.

34. Miao, Q., Eva, N., Newman, A. \& Schwarz, G. (2019). Public Service Motivation and Performance: The Role of Organizational Identification. Public Money \& Management, vol. 39, no 2, pp. 77-85.

35. Miles, M.B. \& Huberman, M. (1994). Qualitative Data Analysis: An Expanded Sourcebook. 2nd ed. Thousand Oaks, CA: Sage.

36. Moynihan, D.P. \& Pandey, S.K. (2007). The Role of Organizations in Fostering Public Service Motivation. Public administration review, vol. 67, no 1, pp. 40-53.

37. National Commission for Civic Education (NCCE) (2017). Survey on Public Perception on the State of Corruption, Public Accountability and Environmental Governance in Ghana. Available at: http://nccegh.org/site/media/researchreport/PUBLIC\%20ACCOUNTABILITY\%20 \&\%20ENVIRONMENTAL\%20GOVERNANCE\%20.pdf (accessed: 15 December 2020)

38. Neumann, O. (2019). "Giving Something Back to Society": A Study Exploring the Role of Reciprocity Norms in Public Service Motivation. Review of Public Personnel Administration, vol. 39, no 2, pp. 159-184.

39. Owusu, F. (2006). Differences in the Performance of Public Organisations in Ghana: Implications for Public-Sector Reform Policy. Development Policy Review, vol. 24, no 6, pp. 693-705.

40. Paarlberg, L.E. \& Lavigna, B. (2010). Transformational Leadership and Public Service Motivation: Driving Individual and Organizational Performance. Public Administration Review, vol. 70, no 5, pp. 710-718.

41. Paarlberg, L.E., Perry, J.L. \& Hondeghem, A. (2008). From Theory to Practice: Strategies for Applying Public Service Motivation. In: Motivation in Public Management: The Call of Public Service, pp. 268-293.

42. Perry, J.L., Hondeghem, A. \& Wise, L.R. (2010). Revisiting the Motivational Bases of Public Service: Twenty Years of Research and an Agenda for the Future. Public Administration Review, vol. 70, no 5, pp. 681-690.

43. Perry, J.L. (1996). Measuring Public Service Motivation: An Assessment of Construct Reliability and Validity. Journal of Public Administration Research and Theory, vol. 6, no 1, pp. 5-22. 
44. Perry, J.L. (2000). Bringing Society. In: Toward a Theory of Public Service Motivation. Journal of Public Administration Research and Theory, vol. 10, no 2, pp. 471-488.

45. Perry, J.L. \& Hondeghem, A. (eds.) (2008). Motivation In Public Management: The Call of Public Service. Oxford University Press on Demand.

46. Perry, J.L. \& Wise, L.R. (1990). The Motivational Bases of Public Service. Public Administration Review, pp. 367-373.

47. Piatak, J.S. \& Holt, S.B. (2020). Prosocial Behaviors: A Matter of Altruism or Public Service Motivation?. Journal of Public Administration Research and Theory, vol. 30, no 3, 504-518.

48. Podsakoff, P.M., MacKenzie, S.B., Lee, J.Y. \& Podsakoff, N.P. (2003). Common Method Biases in Behavioral Research: A Critical Review of the Literature and Recommended Remedies. Journal of Applied Psychology, vol. 88, no 5, p. 879.

49. Rainey, H.G. (1982). Reward Preferences Among Public and Private Managers: In Search of the Service Ethic. The American Review of Public Administration, vol. 16, no 4, pp. 288-302.

50. Ritz, A., Brewer, G.A. \& Neumann, O. (2016). Public Service Motivation: A Systematic Literature Review and Outlook. Public Administration Review, vol. 76, no 3, pp. 414-426.

51. Ritz, A. \& Brewer, G.A. (2013). Does Societal Culture Affect Public Service Motivation? Evidence of Sub-National Differences in Switzerland. International Public Management Journal, vol. 16, no 2, pp. 224-251.

52. Schwarz, G., Eva, N. \& Newman, A. (2020). Can Public Leadership Increase Public Service Motivation and Job Performance?. Public Administration Review.

53. Spector, P.E. (2006). Method Variance in Organizational Research: Truth or Urban Legend?. Organizational Research Methods, vol. 9, no 2, pp. 221-232.

54. Taylor, J. \& Taylor, R. (2011). Working Hard for More Money or Working Hard to Make a Difference? Efficiency Wages, Public Service Motivation, and Effort. Review of Public Personnel Administration, vol. 31, no 1, pp. 67-86.

55. Tullock, G. (1976). The Vote Motive. Sussex, UK: The Institute of Economic Affairs.

56. Kim, S. \& Vandenabeele, W. (2010). A Strategy for Building Public Service Motivation Research Internationally. Public Administration Review, vol. 70, no 5, pp. 701-709.

57. Van der Wal, Z. (2015). "All Quiet on the Non-Western Front?" A Review of Public Service Motivation Scholarship in Non-Western Contexts. Asia Pacific Journal of Public Administration, vol. 37, no 2, pp. 69-86.

58. Yin, R.K. (2003). Case Study Research Design and Methods. Applied Social Research Methods Series. Thousand Oaks, CA: Sage Publications.

59. Yung, B. (2014). Differential Public Service Motivation among Hong Kong Public Officials: A Qualitative Study. Public Personnel Management, vol. 43, no 4, pp. 15-441. 